\title{
Tensile Properties of Natural Rubber Nanocomposites Affected by Crosslink Density
}

\author{
Mohammad Reza Saeb ${ }^{1}$, Raha Sarami ${ }^{2}$, Bijan Iranpak ${ }^{3}$, Ramtin Gaffari ${ }^{4}$ \\ ${ }^{1}$ Department of Resin and Additives, Institute for Color Science and Technology, Tehran, Iran \\ ${ }^{2}$ Technical Faculty, Polymer Group, Tarbiat Modares University, Tehran, Iran \\ ${ }^{3}$ Islamic Azad University, Tehran North Branch, Tehran, Iran \\ ${ }^{4}$ Islamic Azad University, Central Tehran Branch, Tehran, Iran \\ Email: Saeb-mr@icrc.ac.ir
}

Received 2012

\begin{abstract}
The aim of this study was to investigate the tensile properties of the natural rubber nanocomposites containing surface modified calcium carbonate nanofiller. All nanocomposites were prepared at various nanofiller contents, using a laboratory scale two-roll mill. The results revealed that the ultimate tensile properties altered by changing nanofiller content throughout the elastomeric matrix, which could be ascribed to the particular interactions at the filler/matrix interface. At 10 parts by weight of nanofiller, based on 100 parts by weight of natural rubber, the highest value of tensile properties was achieved as a result of crosslink density being at its highest level, as measured by swelling method.
\end{abstract}

Keywords: Natural Rubber Nanocomposites; Calcium Carbonate; Tensile Properties

\section{Introduction}

For a long time, natural rubber (NR) has been considered as an important elastomer from both industrial and academic points of views. Also, there have been many works on dealing with incorporation of inorganic fillers, e.g., silica, calcium carbonate (CC), and clay to diminish the production costs as well as enhancement of ultimate properties of elastomeric matrices. The main issue, however, was to load high levels of this matter within rubber compounds owing to agglomeration. Among micron and nano size CC, the latter was found to be the better one, regarding mechanical and curing characteristics. Employing surface modified CC filler in various elastomeric compounds, in particular in nano scale, has been already reported by several authors [1-3]. Surface modification inhibits the undesired filler-filler interaction; at the same time, enhances the polymer-filler adhesion. The thermo-mechanical properties of butadiene rubber nanocomposites reinforced with modified CC has been shown that both thermal stability and mechanical properties of the prepared nanocomposites highly depend on the size and amount of CC nanofillers. [3] The tensile properties in these systems were considerably improved by increasing the amount of filler up to an optimum content which is ascribed to acceptable intermolecular interactions between the rubber chains and the filler surfaces. Similar trends have been reported by other researchers regarding to incorporation of CC with thermoplastics [4].

In the current work, NR nanocomposites containing surface-coated calcium carbonate (MCC) were prepared by a laboratory two-roll mill and then their tensile and curing characteristics were studied. The MCC nanofiller has already been surface modified with stearic acid, according to the supplier. Tensile strength, elongation at break, and crosslink density data demonstrated considerable changes while employing various amounts of MCC nanofillers.

\section{Experimental}

\subsection{Materials}

NR SMR20 with Mooney viscosity of 65, under brand name of TAYTEX, was purchased from the AH YAU rubber factory and used, as received. The nano-sized precipitated calcium carbonate (NPCCA-201); namely MCC, was purchased from Shandong Haize Nanomaterials Co., Ltd. This matter is a sort of coated calcium carbonate with stearic acid, according to supplier. The mean particle size and specific surface area of the MCC were roughly $50 \mathrm{~nm}$ and $24.51 \mathrm{~m}^{2} / \mathrm{g}$, according to the supplier.

\subsection{Sample Preparation and Characterization}

Based on 100 part of NR rubber, three compounds containing various amounts of MCC (5, 10, 15 phr) were prepared. Table 1 represents the formulation of NR/MCC nanocomposites. In o0rder to better control of curing process, two accelerators are simultaneously used while compounding, the tetramethylthiuram disulfide (TMTD) with melting point of $148^{\circ} \mathrm{C}$ and density of $1.43 \mathrm{~g} / \mathrm{cm} 3$ and dibenzothiazyl disulfide (MBTS) with melting point of $166^{\circ} \mathrm{C}$ and density of $1 \mathrm{~g} / \mathrm{cm} 3$. The former is purchased from Akrochem Corporation, USA and the latter from Meyors, China Chemical Ltd.

The mixing of rubber, zinc oxide, TMTD antioxidant, and stearic acid was carried out using a laboratory open two-roll mill at $60^{\circ} \mathrm{C}$ for $5 \mathrm{~min}$. The gear friction of the mill was 1:1.2. Furthermore, the filler was added to the compound and milled at $60^{\circ} \mathrm{C}$ for $10 \mathrm{~min}$. The prepared sheets, of about $2 \mathrm{~mm}$ in 
thickness, were vulcanized at $160^{\circ} \mathrm{C}$ and 70 bars by using a hydraulic press. Mechanical data were gathered using a $20 \mathrm{kN}$ Zwick apparatus, according to ASTM D412, on the way in which, elongation at break and tensile strength of the produced samples were simultaneously measured. All vulcanized samples were also swollen by toluene to calculate their crosslink densities.

\section{Results and Discussions}

The particle size and particle size distribution of MCC through the NR matrix play important role on ultimate properties. The higher the homogeneity through dispersion of MCC nanofiller into the rubber matrix the better is the interfacial bonding of filler-polymer. Normally, the nanocomposite behavior can be affected by the nature of either matrix or filler [5]. Figure 1 demonstrates the tensile strength and elongation at break data versus MCC content, simultaneously. All tests were repeated five times for every sample and then averaged.

According to this figure, by increasing MCC content from 5 to $10 \mathrm{phr}$, a drastic increase in both tensile and elongation at break of NR nanocomposites were observed. Further increase in the MCC content caused the mechanical properties to decline. In order to investigate the consequence of polymer-filler interaction, crosslink density can be considered as an important factor which tunes ultimate mechanical properties. Polymer chains with restricted mobility are the result of improving polymer-solid interface leading to excess physical crosslinks. Diminishing the average number of intermolecular bonds per unit volume, on account of the structural changes in polymersolid adhesion and also lowering the packing density of the

Table 1. Compounding formulation.

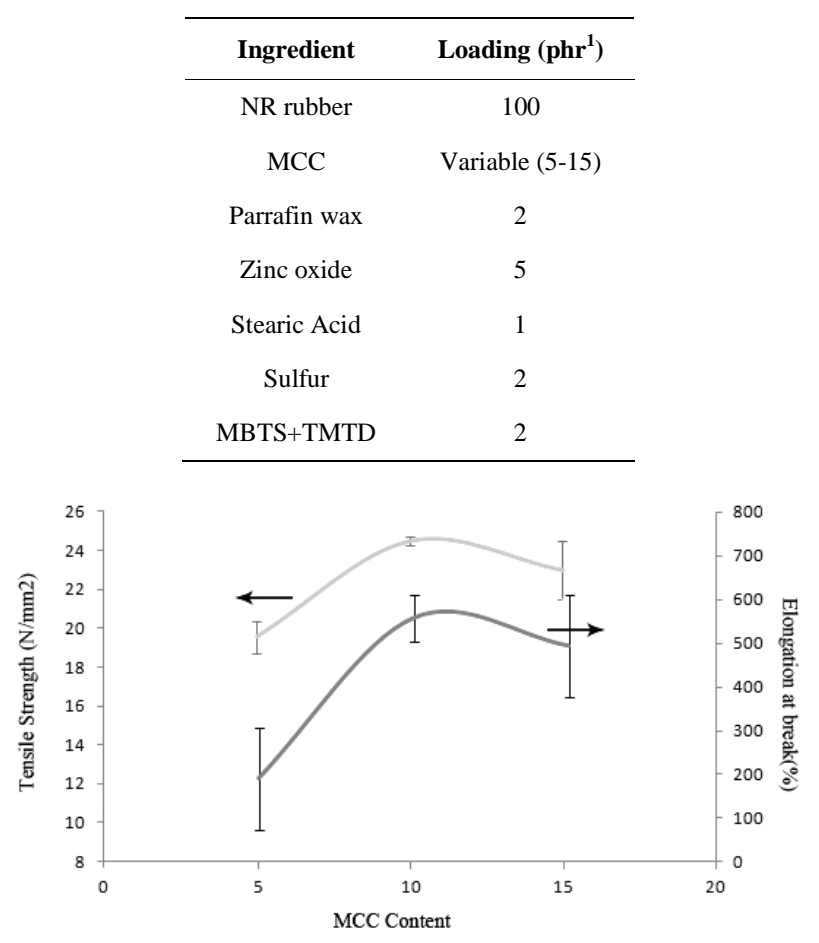

Figure 1. Tensile strength and elongation at break data of NR nanocomposites at different contents of MCC. polymer chains are other probable circumstances.

Ignoring the effect of filler-matrix interactions, all vulcanized samples were swollen by toluene to calculate their crosslink densities through Flory- Rehner equation [8]:

$$
n=\frac{-\left[\operatorname{Ln}\left(1-v_{2}\right)+v_{2}+\chi_{1} v_{2}^{2}\right]}{V_{1}\left(v_{2}^{1 / 3}-v_{2} / 2\right)}
$$

where $\mathrm{n}$ is the crosslink density, $\mathrm{V}_{1}$ is the molar volume of utilized solvent $\left(106.2752 \mathrm{~cm}^{3} / \mathrm{mol}\right), v_{2}$ is the volume fraction of polymer in the swollen sample, and $\chi_{1}$ is the Flory-Huggins polymer-solvent interaction parameter or the enthalpy of mixing, which may be found in the literature[9]or determined by the following equation:

$$
\chi_{1}=\beta_{1}+\frac{V_{1}\left(\delta_{1}-\delta_{2}\right)^{2}}{R T}
$$

where $\beta_{1}$ is the lattice constant of entropic origin and is often assumed to be zero, $\mathrm{T}$ is the medium temperature, $\delta_{1}$ and $\delta_{2}$ and are solubility parameters for solvent (18.2 $\left.\mathrm{MPa}^{0.5}\right)$ and NR rubber $\left(16.69 \mathrm{MPa}^{0.5}\right)$, respectively. The alteration of crosslink density, measured by swelling method, as a function of MCC content is reported in Table 2. It should be mentioned that for every sample, the swelling test was repeated 10 times and the values then averaged.

Based on swelling method and using equations (1) and (2), it was found that the highest value of crosslink density has been achieved in case which the nanocomposite was filled with 10 phr of MCC. In can be speculated that as the number of crosslinks per unit volume increased, the elastic nature of prepare samples got dominant to the viscous effect. In another word, a 3D network with small interlinks comes into exist at assigned filler content. Thus, the tensile properties are definitely affected by the interaction of MCC nanofiller and NR rubber chains at their interface which is traced by crosslink density measurements. It means that the interface of MCC filler with NR matrix is considerably higher, at $10 \mathrm{phr}$ of filler than that of $5 \mathrm{phr}$. However, by further increase up to $15 \mathrm{phr}$, the tensile properties were slightly diminished, as a result of partial agglomeration within the NR nanocomposite, which has been reported elsewhere [5].

\section{Conclusion}

NR-based nanocomposites containing various amounts of surface modified nano calcium carbonate (MCC) were prepared using a laboratory-scale two roll mill. It was found that increasing MCC from 5 to $10 \mathrm{phr}$ within the NR nanocompound results in higher values of tensile strength and elongation at break. The consequences of particle size and particle size distribution were also investigated by measuring crosslink density through the swelling test. All mechanical properties concerning

\begin{tabular}{|c|c|}
\hline Filler content (phr) & Crosslink density* $10^{-5}\left(\mathrm{~mol} / \mathrm{cm}^{3}\right)$ \\
\hline 5 & 9.23 \\
\hline 10 & 9.89 \\
\hline 15 & 9.63 \\
\hline
\end{tabular}

Table 2. Crosslink density as a function of filler content. 
15 phr of MCC were showed to be lower than those obtained for samples containing $10 \mathrm{phr}$ of MCC. According to the results of the swelling test, the highest value of crosslink density was achieved for the sample containing $10 \mathrm{phr}$ of the MCC. Therefore, it can be concluded that the tensile properties are highly affected by the 3D network created in the presence of curing agent and nanofiller.

\section{REFERENCES}

[1] S. Mishra, N.G. shimpi, and U.D.Patil, "Effect on nano $\mathrm{caco}_{3}$ on thermal properties of styrene butadiene rubber (SBR)," J Polym Res, 2007, 14, 449.

[2] C.G.Ma, Y.A.Mai, M.Z.Rong, W.H.Ruan, and M.Q.Zhang, "Phase structure and mechanical properties of ternary polypro-
pylene/elastomer/nano-CaCO3 composites ," Comp Sci Tech. 2007, 67, 2997.

[3] Y.Zhou, S.Wang, Y.Zhang, X.Jiang, and D.Yi, "Rheological properties of PDMS filled with $\mathrm{CacO}_{3}$ : The effect of filler particle size and concentration,”J Appl Poly Sci, 2006, 101, 3395.

[4] H.Hanim, R.Zarina, M.Y.Ahmad Fuad, Z.A.Mohd.Ishak, and Azman Hassan, "The effect of calcium carbonate nanofiller on the mechanical properties and cristallization behavior of polypropylene,"Malay Polym J. 2008 , 3 , 38.

[5] M.R.Saeb, H.Ramezani-Dakhel, H.A.Khonakdar, G.Heinrich, and U.Wagenknecht, " A comparative study on curing characteristics and thermomechanical properties of elastomeric nanocomposites: The effects of eggshell and calcium carbonate nanofillers,”J Appl Poly Sci, 2012, DOI: 10.1002/app.38022. 